\title{
Platelet Adhesiveness after Blood Donation
}

\author{
GEOFFREY D. PEGRUM, KATHLEEN M. HARRISON, SIDNEY SHAW
}

British Medical fournal, 1971, 1, 580-582

\section{Summary}

Platelet adhesiveness to glass was measured in healthy blood donors at the time of and eight days after donating $500 \mathrm{ml}$ of blood. By a whole blood method a highly significant increase was found whereas by a method using platelet-rich plasma with added adenosine diphosphate there was only a slightly significant increase. The discrepancy suggested that changes in the red cell population might influence the results. Packed red cells from 19 blood donors obtained at the time of donation and eight days later were mixed with fresh pooled platelets from the same independent persons on each occasion. The whole blood platelet adhesiveness on this mixture showed an increase in every case after blood donation. It is postulated that the increased adhesiveness is influenced by the presence of young red cells.

\section{Introduction}

Since the first observations by Payling Wright (1942) that after surgical operations there is an increase in platelet adhesiveness many studies have been carried out which confirm this finding. The most commonly used methods have involved whole blood glass adhesiveness. Adenosine diphosphate has also been used to initiate adhesiveness, but the results do not appear to correlate with glass adhesiveness methods (Bennett, 1968). In these studies little notice has been taken of the possible effect of blood loss on the observed alteration in platelet adhesiveness. This would appear important, particularly if one uses a whole blood technique, as the adenosine diphosphate released from the red cells is directly related to the level of adhesiveness obtained (Hellem, 1960). It is possible that alteration in the red cell population at an interval after blood loss may have an effect on platelet adhesiveness. It was therefore decided, firstly, to examine for any change in platelet adhesiveness after blood donation and, secondly, to see if the red cells at the time of donation compared with those eight days afterwards produced any significant change. Recently we have standardized the techniques of platelet adhesiveness by means of glass adhesion (Shaw et al. 1970). Comparisons were made between whole blood and platelet-rich plasma with added adenosine diphosphate.

These two techniques were used on blood samples obtained at venesection of $500 \mathrm{ml}$ of blood from healthy donors and on venous blood taken eight days later. In 19 donors packed red cells were obtained at the same time intervals, and the effect of these cells was observed on the adhesiveness of fresh pooled platelets.

Charing Cross Hospital Medical School, London w.C.2

GEOFFREY D. PEGRUM, M.D., M.R.C.PATH., Senior Lecturer in Haematology

KATHLEEN M. HARRISON, M.B., M.R.C.PATH., Lecturer in Haema-

tology
SIDNEY SHAW, M.D., F.R.C.PATH., Head of Department of Haematology

\section{Subjects and Methods}

Venous blood was obtained at the time of taking $500 \mathrm{ml}$ of blood from 60 healthy blood donors aged 19 to 60 (32 men and 28 women). For technical reasons the first blood samples were obtained at the end of the blood collection with the plastic tubing of the blood-taking set. In each case the blood was taken in the morning before lunch, but a variable time after an unspecified breakfast, and the amount of exercise or smoking before the tests were performed was not controlled. The second sample of venous blood obtained eight days later was taken at roughly the same time of day and the donors were asked to follow the same habits as on the day of blood donation.

The blood samples $(7 \mathrm{ml})$ were placed immediately in plastic containers with $3.13 \%$ trisodium citrate in a dilution of 1:12. The blood and anticoagulant were mixed by gently inverting 15 times. The methods used for adhesiveness were as described (Shaw et al., 1970). All the techniques were rigidly controlled, and the adhesive tests were carried out on each occasion at the same interval after obtaining the blood from each donor.

\section{TECHNIQUES OF PLATELET ADHESIVENESS}

Whole Blood Method.-The citrated blood was passed through a column of glass microspherules, of diameter between 0.102 and $0.124 \mathrm{~mm}$, which had been acid cleaned and then prepared by repeated washing and finally dried in a hot air oven. The blood was forced through the column, which was of standard dimensions, by a mechanical system which delivered exactly $1 \mathrm{ml}$ of blood in seven seconds; $2 \mathrm{ml}$ of blood was passed through the column in this way, taking exactly 14 seconds. Twenty seconds after the start the sample which had been passed through the column was collected in a plastic tube containing $2.4 \mathrm{mg}$ of edetic acid and gently mixed for 20 seconds. A platelet count was carried out on this and on a specimen of the initial blood sample. The difference in platelet count was regarded as the adhesive count, which was expressed as a percentage of the initial platelet count.

Platelet-rich Plasma Method.-Platelet-rich plasma was obtained by centrifuging a specimen of citrated blood at 1,500 r.p.m. for 15 minutes. Adenosine diphosphate $0.5 \mu \mathrm{g} / \mathrm{ml}$ was added to the plasma after an initial platelet count had been made. After the addition of adenosine diphosphate the plasma was mixed 10 times by gentle inversion. Then $2 \mathrm{ml}$ was drawn up into a plastic syringe and exactly one minute after the addition of adenosine diphosphate was passed through a column of glass microspherules prepared in the same way as for the whole blood adhesive method. Plasm? passing through the column at uniform rate was collected in a polystyrene tube containing $2.4 \mathrm{mg}$ of edetic acid and gently mixed for 20 seconds, the time intervals and collection being exactly the same as for the whole blood adhesiveness technique. The level of adhesiveness was calculated in the same way.

Use of Donor Cells.-This experiment was carried out on red cells obtained at the time of the blood donation and eight days afterwards. The same platelet donors were used on each occasion. Seven millilitres of blood was collected from the donor into $3.13 \%$ trisodium citrate to give a final dilution of 
1:12. After mixing, this was centrifuged at 3,000 r.p.m. for 15 minutes at $4^{\circ} \mathrm{C}$. The plasma and about $1 \mathrm{ml}$ of the underlying cells were removed and discarded. The remaining packed red cells were used after storing at $4^{\circ} \mathrm{C}$ for one to two hours. Pooled normal platelets were prepared from two healthy persons of the same blood group as the blood donor. Venous blood from each was taken into $3.13 \%$ trisodium citrate to give a 1:12 dilution and centrifuged at 1,500 r.p.m. for 15 minutes at room temperature. Equal quantities of the platelet-rich plasma were removed from both samples and mixed together for two minutes on a Matburn wheel. Then $1.5 \mathrm{ml}$ of the pooled platelets was added to $1.5 \mathrm{ml}$ of packed cells and after mixing for two minutes was left to stand at room temperature for one hour to conform with the regimen used for the whole blood method. The blood was then remixed, a platelet count performed, and the whole blood adhesiveness estimated as previously described.

\section{Results of Adhesiveness Studies}

Whole Blood.-The whole blood adhesiveness was performed on 60 healthy donors. The level was found to be increased one week following venesection in 49 donors, equal in 2 , and reduced in 9 (Fig. 1). Comparison of the paired results obtained showed that there was a significant increase in the platelet adhesiveness eight days after the loss of $500 \mathrm{ml}$ of blood $(\mathrm{P}<0.001)$.

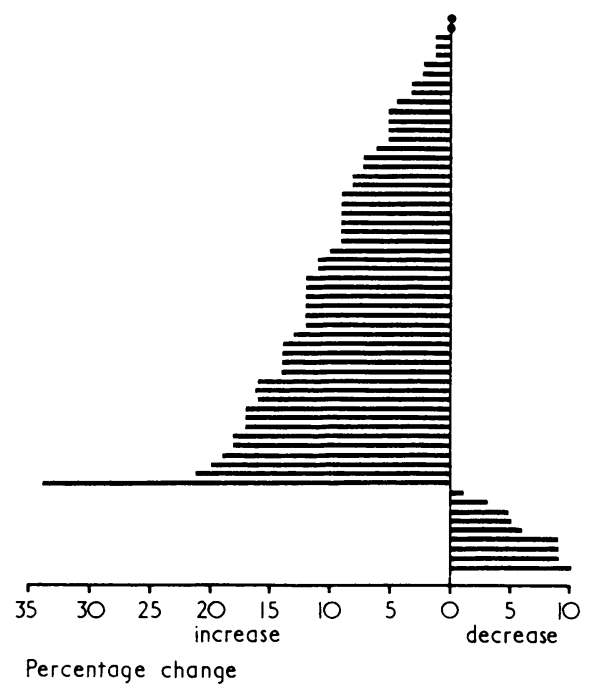

FIG. 1-Platelet adhesiveness : whole blood. Percentage change from time of venesection to eight days later in 60 donors.

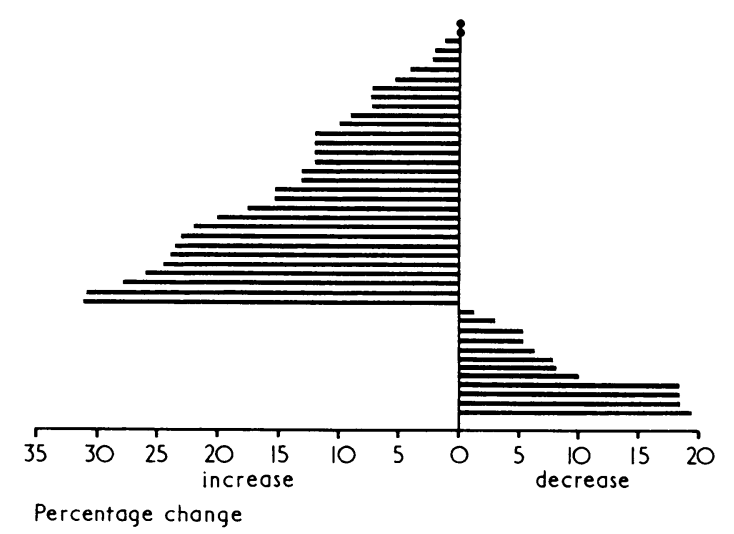

FIG. 2-Platelet adhesiveness: platelet-rich plasma with added adenosine diphosphate. Percentage change from time of venesection to eight days later in 43 donors.
Platelet-rich Plasma with Adenosine Diphosphate.-Of the 43 donors studied with this technique, 29 showed an increased adhesiveness after eight days, 2 were unchanged, and 12 showed a reduction of platelet adhesiveness (Fig. 2). The paired results do not show the same significance as those found with the whole blood $(0.05>P>0.025)$.

Effect of Donor Red Cells.-In the 19 donors the red cells produced increased adhesiveness of the independent platelets eight days after blood donation in 18 and no change in one (Fig. 3). The comparison of the paired results is highly sig-

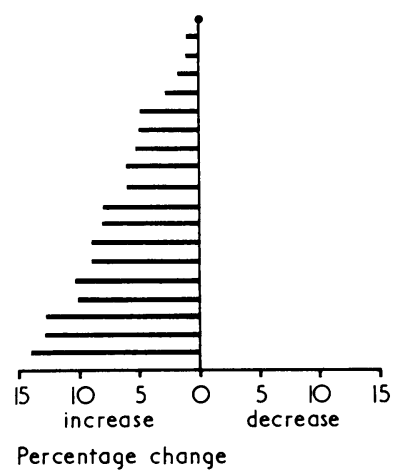

FIG. 3-Platelet adhesiveness: packed red cells with normal pooled platelets. Percentage change from time of venesection to eight days later in 19 donors.

nificant statistically $(P<0.001)$. In eight of these donors platelet adhesiveness was compared at the same time using their own platelets by the whole blood and platelet-rich plasma methods as described above. With whole blood the adhesiveness was increased in seven but decreased in one donor eight days after blood donation. With platelet-rich plasma it was increased in six but decreased in two donors. No significant conclusion can be drawn from these findings, but the fact that two of the eight donors showed a decrease in adhesiveness in the platelet-rich plasma method suggests that this might be associated with absence of red cells, especially young red cells.

\section{Discussion}

It was previously shown (Shaw et al., 1970) that if the conditions of the techniques are rigidly controlled there is a significant correlation between platelet adhesiveness to glass when using whole blood and platelet-rich plasma with added adenosine diphosphate in healthy subjects. Comparison of the two techniques in parallel on a series of healthy blood donors at the time of venesection of $500 \mathrm{ml}$ and eight days later showed a disparity in the increase in platelet adhesiveness, the whole blood method showing a more significant increase than the adenosine diphosphate platelet-rich plasma method. A similar postoperative change was described by Bennett (1968). These findings suggest that the red cells probably play a key part, accounting for the difference.

In an attempt to discover the part played by the change in red cell population, an experiment was made with red cells from the donors obtained at the time of venesection and eight days later. In this experiment the pooled platelets were freshly obtained at a fixed time after the red cells were collected from the blood donors. In each case it was shown that the red cells taken from the blood donors eight days after venesection increased the level of platelet adhesion. It seems likely that the presence of a higher proportion of younger red cells in the circulation of the donors a week after blood loss probably accounts for these changes. Karpatkin 
(1969) found that young platelets have a shorter aggregation time after the addition of adenosine diphosphate. The minor increase in adhesiveness that we found when using plateletrich plasma may well reflect a change in platelet population after blood loss.

Reticulocyte counts were not carried out on the blood samples tested. It was thought unlikely that there would be any significant change in healthy persons eight days after donating $500 \mathrm{ml}$ of blood, and that this index would not be sufficiently sensitive to measure the shift in red cell population which we consider causes the changes in adhesiveness. Reticulocytosis indicating an obvious increase in young red cells might well influence platelet adhesiveness, and we have been carrying out further experiments and collecting data on patients with an increase in reticulocytes.

Any estimation of postoperative changes in adhesiveness, especially when using a whole blood method, must be interpreted with due regard to the degree of blood loss in the patient as it is apparent that this by itself can produce increased adhesiveness. It is likely that the more severe the blood loss the greater the expected increase in adhesiveness, this probably depends on the number of young red cells in the peripheral blood as well as the increase in young platelets.
After operation there is an increase in platelet adhesiveness as well as an increase in venous thrombosis. It would be of interest to know whether adequate replacement of blood loss at operation with suppression of marrow activity would reduce this increase in adhesiveness with associated venous thrombosis.

We should like to thank the Red Cross blood donors who kindly consented to take part in these investigations and Professor D. L. Mollin who agreed that we might ask the donors to assist. We wish to thank Mrs. Sylvia Wolff. Miss Angela de Jong. and Miss Charis E. Jocelyn for skilled technical help. We are grateful to the Subcommittee for Clinical Research, Charing Cross Hospital, for financial support.

Requests for reprints should be addressed to Dr. Sidney Shaw.

\section{References}

Bennett, P. N. (1968). Fournal of Clinical Pathology, 21, 695.

Hellem, A. J. (1960). Scandinavian Fournal of Clinical and Laboratory Investigation, 12, Suppl. No. 51.

$\mathbf{K}$ arpatkin, S. (1969). Fournal of Clinical Investigation, 48, 1083.

Shaw, S., Pegrum, G. D., and Wolff, S. (1970). Fournal of Clinical Pathology,

23, 144.
Wright, H. Payling (1942). Fournal of Pathology and Bacteriology, 54, 461.

\title{
Radioimmunoassay of Human Serum Thyrotrophin
}

\author{
REGINALD HALL, JACQUELINE AMOS, BRIAN J. ORMSTON
}

British Medical fournal, 1971, 1, 582-585

\section{Summary}

The double antibody radioimmunoassay of serum thyroidstimulating hormone (TSH) allows measurement of circulating levels of the hormone in most normal subjects. The serum TSH level in normal subjects is $1.6 \pm 0.8 \mu \mathrm{U} / \mathrm{ml}$. Patients with non-toxic goitre and acromegaly have normal TSH levels. Values are always raised in hypothyroid patients (with primary thyroid disease) and are significantly lowered in those with hyperthyroidism. Of the many stimuli used in an attempt to raise TSH levels in normal adult subjects only three-synthetic thyrotrophin-releasing hormone, ethinyloestradiol, and carbimazole plus iodides-have been effective. The major clinical application of the TSH immunoassay lies in the diagnosis of minor degrees of hypothyroidism. An impaired response of serum TSH to synthetic thyrotrophinreleasing hormone should also help in the diagnosis of hypopituitarism affecting TSH production.

\section{Introduction}

Specific radioimmunoassays of human thyroid-stimulating hormone (TSH) have been described by Odell et al. (1965), Utiger (1965), and Webster and Greenwood (1968). So far there have been only brief reports of the results of TSH

\footnotetext{
Department of Medicine, University of Newcastle upon Tyne, Newcastle upon Tyne NE1 4LP

REGINALD HALL, M.D., F.R.C.P., Professor of Medicine

JACQUELINE AMOS, Chief Technician

BRIAN J. ORMSTON, M.B., B.S., Research Fellow
}

immunoassays in normal subjects and patients with various thyroid diseases from the U.K. (Hall et al., 1970a; Kirkham et al., 1970; Hall and Amos, 1971). Now that the materials required for the TSH immunoassay are readily available it seems likely that the method will be adopted in most major centres. This report outlines our current double antibody immunoassay for TSH and describes its clinical and physiological applications.

\section{Materials and Methods}

Reagents.-Human TSH supplied by the National Pituitary Agency is used for iodination. Standard human TSH is obtained from the Medical Research Council (M.R.C. Standard A). Initially rabbit anti-TSH antisera obtained from the National Pituitary Agency and from Professor D. Munro were used. Results presented here, however, are derived from the use of a guinea-pig anti-TSH antiserum prepared in Newcastle with TSH fraction DEAE II supplied by Dr. A. Hartree. This antiserum has a higher specificity and avidity than currently available rabbit antisera. Rabbit anti-guinea-pig gammaglobulin was produced locally and tested against ${ }^{131}$ I-labelled guinea-pig gammaglobulin. At the dilution $(1 / 10)$ used in the assay more than $90 \%$ of labelled gammaglobulin can be precipitated after overnight incubation.

Iodination Procedure.- ${ }^{131}$ I labelled TSH is prepared by the chloramine-T method of Hunter and Greenwood (1962) with Amersham IBS 3 carrier-free ${ }^{131}$ I. Five microgrammes of TSH in $10 \mu \mathrm{l}$ of $0.01 \mathrm{M}$ phosphate buffer $\mathrm{pH} 7.4$ is added to $2 \mathrm{mCi}$ of ${ }^{131} \mathrm{I}$, followed by the addition of $50 \mu \mathrm{g}$ of chloramine-T in $10 \mu \mathrm{l}$ and then sodium metabisulphite $250 \mu \mathrm{g}$ in $100 \mu \mathrm{l}$. After removal of an aliquot of the iodination mixture for electrophoresis, 131 Ilabelled TSH is purified by a modification of the method of Yalow and Berson (1966). Amberlite IRA 400 (Cl) is added to remove ${ }^{131} \mathrm{I}$ and, after separation, $50 \mathrm{mg}$ of Quso is added to the supernatant to adsorb undamaged TSH. The Quso is washed four 